\title{
Properties of Archaeological Pottery Tile Excavated from Sanyangzhuang Site Henan, China
}

\author{
J.C. CHEN \\ ${ }^{1}$ Henan Provincial Institute of Cultural Relics and Archaeology, Zhengzhou 450000; \\ ${ }^{2}$ Henan Provincial conservation center, Zhengzhou 450000;
}

X. HUANG

School of Materials Science and Engineering, Zhengzhou University, Zhengzhou 450002;

H.W. LIU, R.SH. ZHU
Henan Provincial Institute of Cultural Relics and Archaeology, Zhengzhou 450000;

ABSTRACT: Sanyangzhuang settlement sites is a ancient villages, which are flooded by the Yellow River in early Western Han Dynasty. A large number of pottery tiles as a part of ancient villages excavated from Sanyangzhuang sites has great value in the study of early Chinese village building. In order to preserved those well, we analyzed the properties of pottery tile by XRD (X-ray diffraction), ESEM (Environment scanning electron microscope) and Electronics omnipotent material trial instrument for the component, structure and mechanical. The results shown that the pottery tile's main ingredients is silicide with loose structure, low mechanical strength and high salt content, which is main reasons for pottery tile weather.

KEYWORD: Han Dynasty; settlement sites; excavated; pottery tile; property

\section{INTRODUCTION}

SanYangZhuang Han Dynasty sites is located SanYangZhuang village, Liang Zhuang Town, Neihuang County. The Han Dynasty Village was submerged due to the ancient the Yellow River massive flooding. It was discovered because of a plan of local government to extend the river in June, 2003. It was named the new discovery is one of the ten greatest archaeology " in 2005, and was appoved by the State Council as the Sixth Batch of national key cultural relics protection units" and included in the national "eleven five" 100 great site protection project in 2006. It was also listed selected the first batch of National Archaeological Site Park project in 2010.

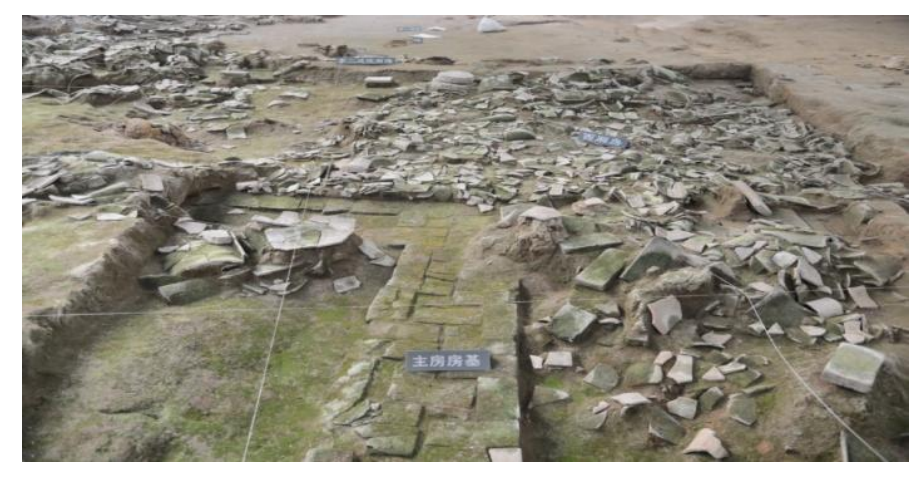

Fig.1 Sanyangzhuang settlement sites

So far, there were 12 courtyard foundations have been confirmed. With excavating 4 of the courtyards, we found a number of important relics, such as house tile roof, wall, water wells, toilets, pond, farmland, and some trees. The results involved in courtyard and living environment of the Han Dynasty people whose life condition below average, which reveals their life environment, fills in gaps of archaeological research, and provides valuable information for studying on the social structure, social system, form the level of agricultural production, building structure and layout, folk custom and economic development of the Western Han Dynasty, can be called "Chinese Pompeii".

A large number of precious cultural relics unearthed from the site reflect the living condition and the production at that time, the real scene of Han agriculture village, especially Han vernacular architecture remains preserved well provides very valuable and important information for study on general residential buildings and technology the Han Dynasty [1-3].

Chinese architectural pottery and firing started to be used from the early Shang Dynasty. During the Qin and Han Dynasties, with the rapid development of social productivity and handicraft industry, the pottery industry made a spurt of progress in production scale, technology the quantity and quality which exceeded any previous era. Especially the portrait brick Qin Dynasty and Han tile, which used as a building created precedent of tile roof building. It is the most distinctive that used as not only to protect the building from the wind and rain erosion, but with great decorative effect [4-5]. 
Because the SanYang Zhuang Han settlement sites has been submerged by Yellow River water flooded resulted in the ruins contained a large number of soluble salt. After excavation, with water evaporation the soluble salt precipitation on the soil surface resulted in more serious weathering and crisp alkali disease, which made the long-term preservation of Terra cotta become more difficult. Therefore, how to take the advanced means to solve the terracotta's diseases is the key problem in protection processing. Analysis of the basic properties of SanYang Zhuang ruins unearthed terracotta in this article, in order to provide the basic data for the scientific conservation site in future.

\section{EXPERIMENT}

\subsection{Preparation of sample s}

The terracotta sample from the sites show graphite color that indicates it should be prepared under a reducing atmosphere at high temperature sintering. We take the maximum value in thickness, according to the test requirements have the samples cut into $6 \mathrm{~cm} * 3 \mathrm{~cm} * 2 \mathrm{~cm}$ in long width high respectively. Then put them into oven, drying in $103{ }^{\circ} \mathrm{C}$ to constant weight for use.

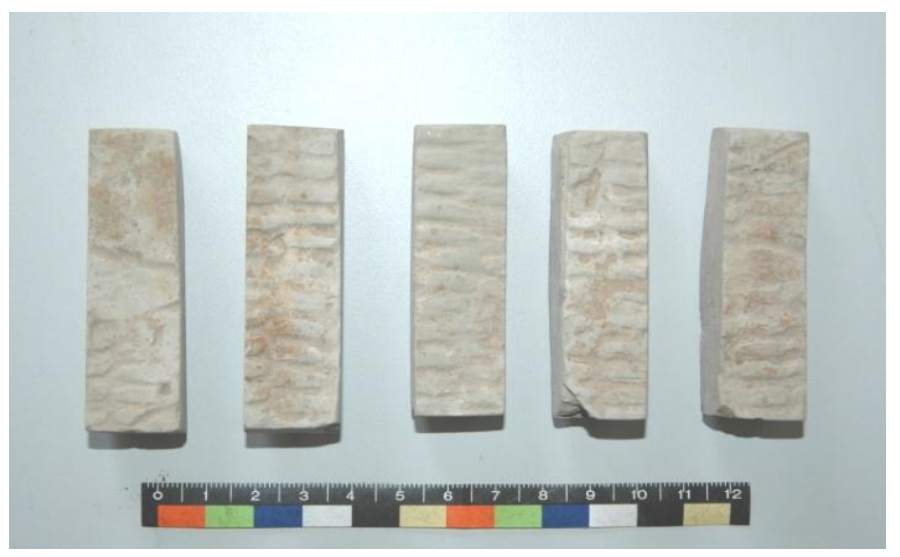

Fig. 2 sample for characterizing

\subsection{Methods}

The component and content of soluble salt in terraocatta were analyzed by Ion Chromato (TA: Result and Discussion ICS-1100); XRD of the samples were recorded by Bruke D8 Focus $\mathrm{XRD}\left(\mathrm{Cu} / \mathrm{Ka}, 15.4 \mathrm{~nm}, 40 \mathrm{Kv}, 100 \mathrm{~mA}, 50 / \mathrm{min}, 5-70^{\circ}\right) . \mathrm{M}$ icrostructure of samples were characterized by FEI/Quanta 650ESEM and EDAX. Compressive strength of sample were recorded by Instron 3360(pts/sacs: 10.000; humidity: (\%): 50; ( $\mathrm{mm} / \mathrm{min})$ : 25.0000; Temp: $25^{0} \mathrm{C}$ ).

\subsection{Component and Content of salt}

As shown in Table1and Fig3, there were higher content of soluble salt in unearthed terracotta, most anion are $\mathrm{SO}_{4}{ }^{2-}$, and most of cation are $\mathrm{Ca}^{2+}$.
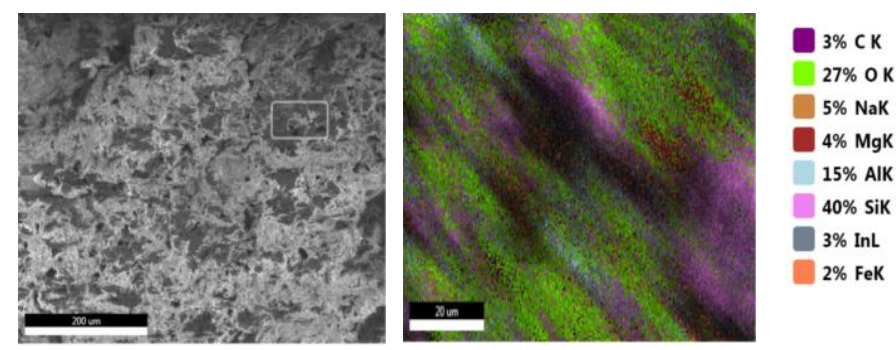

Fig.3 map of element

Table 1 content of cation and anion inside samples

\begin{tabular}{|c|c|c|c|}
\hline anion & content $(\mathrm{mg} / \mathrm{kg})$ & anion & content $(\mathrm{mg} / \mathrm{kg})$ \\
\hline $\mathrm{Na}^{+}$ & 163 & $\mathrm{Cl}^{-}$ & 41.6 \\
\hline $\mathrm{K}^{+}$ & 23 & $\mathrm{NO}^{3-}$ & 143.2 \\
\hline $\mathrm{Mg}^{2+}$ & 68 & $\mathrm{SO}_{4}{ }^{2-}$ & 689.5 \\
\hline $\mathrm{Ca}^{2+}$ & 236 & $\mathrm{CO}_{3}{ }^{2-}$ & 38.9 \\
\hline
\end{tabular}

\subsection{Analysis of structure and properties}

Terracotta artifacts were made of clay minerals by high temperature sintering. Which usually composed of quartz, feldspar, calcite, mica minerals and a small amount of organic detritus[6-10]. As shown in Figure 4, the main species of terracotta unearthed from SanYangzhuang settlement site are quartz, minor phase albite and anorthite.

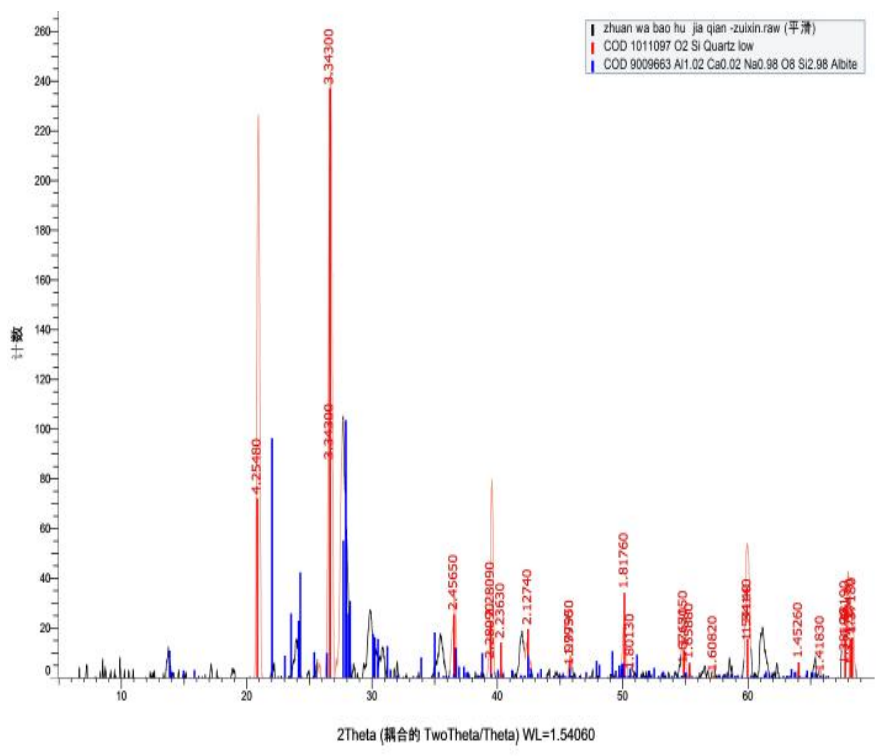

Fig.4 XRD of Terracotta

As shown in Fig5, according to the map of EDS, it mostly made up of $\mathrm{Si}, \mathrm{O}$ and some metal ion, such as : $\mathrm{Na}^{+} 、 \mathrm{~K}^{+} 、 \mathrm{Ca}^{2+} 、 \mathrm{Al}^{3+} 、 \mathrm{Mg}^{2+} 、 \mathrm{Fe}^{2+}$ and so on. The content of each element are listed. 


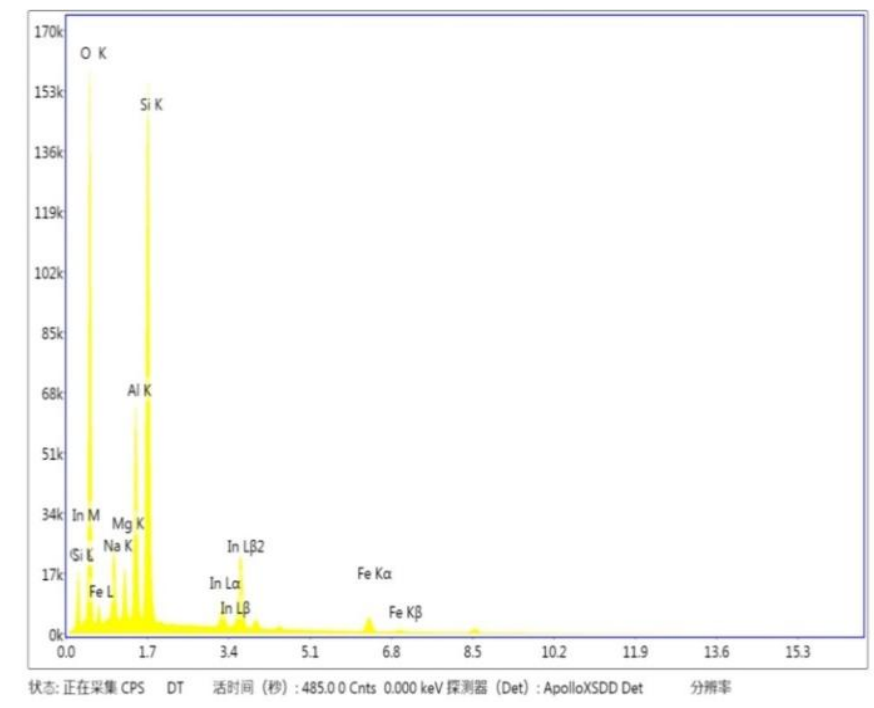

Fig.5 EQUA element

\subsection{Analysis of Microstructure and mechanical}

As shown in Fig 6, the SEM of Terracotta indicates the tile body structure is loose and porous structure, and the pore size and distribution is hetergenous due to manufacturing defects might result in the pore structure; on the other hand, During the firing adobe process, clay with different mineral, size different shrinkage of organic matter and pore fluid will result in uneven distribution. This structure make ceramic relics susceptible to be etched by soluble salt in groundwater in long-term buried underground environment.
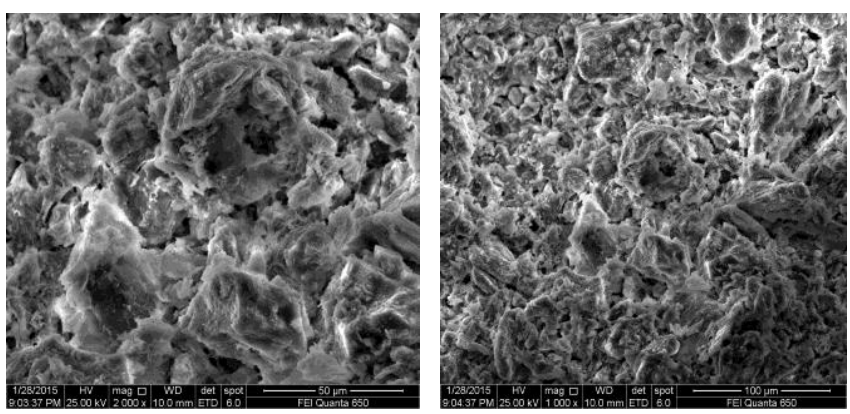

Fig. 6 SEM of Terracotta

The mechanical properties of terra-cotta as shown in Table 2, the results indicate the terra-cotta has high brittleness.

Table 2 bending resistance of terra-cotta

\begin{tabular}{|c|c|c|c|}
\hline No. & $\begin{array}{c}\text { Bending stress } \\
/ \mathrm{MPa}\end{array}$ & $\begin{array}{c}\text { Bending load } \\
/ \mathrm{N}\end{array}$ & $\begin{array}{c}\text { Bending distance } \\
/ \mathrm{mm}\end{array}$ \\
\hline 1 & 870.06067 & 116.00809 & 0.00041 \\
\hline 2 & 939.97518 & 117.49690 & 0.00045 \\
\hline 3 & 954.57446 & 119.32181 & 0.00048 \\
\hline Ave. & 921.53673 & 117.60893 & 0.00046 \\
\hline
\end{tabular}

\section{CONCLUSION}

The main component of torracotta unearthed from SanYangZhuang Han Dynasty sites is silicide with loose porous structure and low mechanical. The soluble salt content is higher. After terra cotta unearthed, the soluble salt invaded into cultural relics will cause "dissolving crystalline" cycle phenomenon, when the environmental temperature and humidity changes. The volume change of the soluble salt in this process will result in the terracotta surface crisp powder and other diseases. Therefore, factors have directly effect on the diseases of unearthed terracotta have been proved as follow: osteoporosis, erosion of soluble salt cultural ontology structure and low mechanical strength and so on.

\section{ACKNOWLEDGEMENT}

This study is supported by the key projects of scientific and technological in Henan Province. No: 072102360010 .

\section{REFERENCES}

[1] Liu Haiwang, Zhang Lvpeng. The Domestic First Discovery of Han Dynasty Village Site. Ancient and Modern Agriculture, 2008, 3: 68-71.

[2] Chen Youwei. Flood site of Sanyangzhuang and the flood of Yellow River during Western Han Dynasty. Academic Journal of Zhongzhou, 2008, 166 (4):172-178.

[3] Sun Zhan. Separated by two thousand years of gaze and reverie. China News Week, 2006, 29:68-70.

[4] Li Jiazhi. Historical role Qin brick and Han tile. Journal of building materials, 1998, 1: 26-31.

[5] Li Naisheng, He Nu, Mao Zhenwei, et, al. Analysis on flat tiles unearthed from Taosi site. Archaeology, 2007, 9:8793.

[6] Lopez A P. Bricks in historical buildings of Toledo City: characterisation and restoration. Materials Characterization 2003, 50:59-68.

[7] Paula L A, Javier G G, Mercedes G, et al. Bricks in historical buildings of Toledo City: characterisation and restoration. Materials Characterization, 2003, 50 (1): 5968.

[8] Lopez A, J Garcia. Weathering traces in ancient bricks from historic buildings. Building and Environment, 2005, 40 (8): 929-941.

[9] J A Larbi. Microscopy applied to the diagnosis of the deterioration of brick masonry. Construction and Building Materials, 2004, 18 (3): 299-307.

[10] Cultrone G, D L Torre, Sebastia, et al. Behavior of brick samples in aggressive Environments. Water, Air, and Soil Pollution, 2000, 119: 191-207. 